\title{
Internet censorship: access issues for school librarians in a cyberspace world
}

\author{
ALVIN M. SCHRADER \\ School of Library and Information Studies, University of Alberta, \\ Edmonton, AB, Canada T6G 2J4, email: \\ alvin.schrader@ualberta.ca
}

\begin{abstract}
Converging communication technologies offer mesmerizing potentialities for global access to local culture. However, concerns about controversial images and ideas on the Internet have inspired both political and technological challenges to open access. Over the past two or three years, a bewildering array of software products has appeared on the U.S. and Canadian markets that claim to be able to either "filter" or "rate" Intemet-based content. Typical product claims are couched in the ihetoric of child protection and parental guidance.

In the cyberspace universe of instant access to infomation and images of all kinds, how should school librarians around the world respond to these commercial products? How can they find a reasonable balance between the sometimes conflicting goals of parental responsibilities, children's educational and developmental interests, media literacy, and community standards?

In view of what appears to be a growing political resolve in many countries to impose technological controls on Intemet content, and a trend towards more and more labeling of creative expression in just about every other medium of communication, it is timely for librarians in all sectors to examine these issues and address the implications for infomation access. The topic of Internet filters is an exciting one for librarians because it represents the intersection of our roles as advocates for intellectual freedom, as organizers of information, and as promoters of media literacy. It gives us the opportunity to share our knowledge and expertise, and to increase our contribution to society at large and around the world.
\end{abstract}

\section{Introduction}

The purpose of this paper is to describe and critique emerging issues about Internet access in schools and school libraries. Recent IASL conferences and the school library literature have begun to report research into the curricular and pedagogic implications of the Internet as a teaching tool, and will no doubt continue to do so. This paper addresses more specific concerns about ongoing efforts by politicians, government agencies, lobby groups, and software entrepreneurs to regulate, restrict, and censor expressive content on the Internet.

There are three bodies of theory and principles forming part of the foundational knowledge of library and information studies that offer a framework for thinking about the

Education for All: Culture, Reading and Information, IASL, 1998 
theoretical feasibility of controlling Internet content. They are 1) intellectual freedom, 2) indexing and retrieval theory, and 3) reader response theory. In a nutshell, what they reveal is a whole set of intractable barriers that render perfect control over expressive content in any communications medium an impossible ideal. These barriers issue from the unsolvable problems of ambiguity in language, indexing, and reading.

\section{Intellectual freedom and the Internet}

Converging communication technologies offer mesmerizing potentialities for global access to local culture (more precisely, they create electronic access to digital versions of ideas, information, stories, images, and sound). At its deepest level, the Internet is praised as one of the most democratic media yet to be invented, "a babble of millions of ungoverned and ungovernable voices" (Book and Periodical Council 1997, 14). I suspect that we have all heard the Internet missionaries wax eloquent about the unprecedented and irrepressible freedom of the new communications technology of the Internet, and about its unstoppable, ubiquitous capacity for democratic liberation throughout the world.

However, the sheer scope of the Internet also ensures that "rarely before has the juxtaposition of the thoughtful and the thoughtless, the informed and the ignorant been so starkly defined" (Overview 1997, 1). Or, as Karen Schneider described it recently, the Internet brings together "the good, the bad, the ugly, the inaccurate, and the outdated" (Schneider 1997b, xiii).

What troubles many people is precisely this sort of juxtaposition. The Internet makes accessible not only the generally positive aspects of recorded cultures but also all of the elements that may be considered repugnant and offensive by someone, somewhere, at some time. Such offense is typically prompted by representations of sex, sexuality, nudity, violence, hatred, profanity, religious belief, political ideology, gender, class, race, and power relations that vary from those finding favor within one's own system of group customs and values. And for parents, exposure of children and adolescents to these objectionable representations magnifies the clash of cultures. As a consequence, what follows close on the heels of euphoria over the liberating possibilities of the Internet are fear and panic.

But this is not a late-20th century phenomenon. Throughout recent history, every new technology for public communication-from the printing press in the 15th century to the major 19th and 20th century inventions of photography, motion pictures, sound recordings, radio, television, video, and the Internet-has been greeted by the established order with alarm and foreboding. Be it church, state, or individual citizen, the response has been an effort to control access to ideas, images, and sound that threaten those with power and influence.

This tendency is no less apparent today. While some advocates describe the Internet as a highly decentralized medium in which users have effective control, recent events around the world show how deeply vulnerable and fragile Internet communication is in the face of political and social resolve to regulate it. Indeed, single-minded politicians and lobby groups are now at work in many countries-democratic and otherwise-to push for the control of expressive content on the Internet through the application of current law and through new legislative initiatives. Some countries require that Internet service providers 
and users be registered with the police, and in those and others, regulations allow for the monitoring of political and religious content. In other countries, Web sites are not normally available to individuals at all, and Internet service providers are required to work through gateways controlled and monitored by the state. In some jurisdictions, there is only one service provider for the entire country.

In the U.S., politicians at both state and federal levels have introduced new legislation to control Internet content. The so-called Communications Decency Act is the most egregious example to date on a large scale in a democratic country. This Act, part of the Telecommunications Act passed by the U.S. Congress in 1996, was struck down by the Supreme Court in June 1997 on the eve, fittingly, of the annual conference of the American Library Association. This legislation would have made it a criminal offence, punishable by up to two years imprisonment and/or substantial fines, to knowingly send or display material that could be interpreted as indecent or patently offensive by contemporary community standards in a manner available to minors under 18-material that potentially would have included medical information such as descriptions of childbirth, abortion or sexually related medical conditions, great works of art containing nudes, or even photographs of statues and sculptures of nudes. So even though the First Amendment in the U.S. apparently prevents just this kind of congressional initiative, it seems American politicians saw no harm in trying to circumvent constitutional proscriptions in the interests of scoring political points with a segment of American voters.

The North American marketplace has also responded to Internet fears. Over the past two or three years, a bewildering array of software products has appeared on the U.S. and Canadian markets that claim to be able to either "filter" or "rate" Internet-based content. Typical product claims are couched in the rhetoric of child protection and parental guidance.

In the cyberspace universe of instant access to information and images of all kinds, how should school librarians around the world respond to these commercial products? What is the role of school librarians in the Internet content transmission chain? How can they reconcile the sometimes conflicting goals of parental responsibilities with children's educational and developmental interests, media literacy, and community standards? Can they find a reasonable balance between cyber-access and concerns about undesirable images and information?

More specifically, what is the purpose of Internet filters? Are they sensible tools for librarians in all sectors to use to identify and describe creative content on the internet, in the interests of child protection and social responsibility? Or are they merely the latest technologies for censorship? Do they result in viewpoint discrimination, in restricting or suppressing non-conforming expression? What about children? Do Internet filters and other kinds of content rating systems help parents and librarians protect children?

In view of what appears to be a growing political resolve in many countries to impose technological controls on Internet content, and a trend towards more and more labeling of creative expression in just about every other medium of communication, it is timely for librarians in all sectors to examine these issues and address the implications for information access. The topic of Internet filters is an exciting one for librarians in all sectors because it represents the intersection of our roles as advocates for intellectual freedom, as organizers of information, and as promoters of media literacy. It gives us the opportunity to share our 
knowledge and expertise, and to increase our contribution to society at large and around the world.

This is particularly true because the common perception among both advocates and critics of Internet filtering and rating products is that regulating Internet access is a technological problem. Almost everyone invokes technology-based arguments. Supporters and product owners claim that current software limitations will be overcome as the technology improves, detractors that the software will not work due to its technological limitations. To date, public discourse has been fixated on machines as the central issue.

\section{Software products for filtering and rating expressive content on the Internet}

Filtering software products are designed to perform at one or more levels of computer configuration, ranging from the individual computer workstation or local area network, to a remote vendor server, an ISP (Internet service provider), and other arrangements.

Among the more than 40 products originating in the U.S. and available commercially at the present time are Bess/ $\mathrm{N} 2 \mathrm{H} 2$, CyberPatrol, CyberSitter, CyberSnoop, I-Gear, Internet Filter, Library Channel, NetNanny, NetShepherd, On Guard, Parental Discretion, Rated-PG, SafeSurf/LibrarySafe, SmartFilter, SurfWatch, Tattle-Tale, WebSense, and X-Stop. CyberPatrol, which has partnerships with Microsoft, Netscape, America Online, CompuServe, and Prodigy, among other corporations, claims to dominate 85 percent of the worldwide filtering market (Schneider 1997b, 146).

These products offer a rather bewildering array of software options for controlling and suppressing expressive content on the Internet:

- "bad word," "bad phrase," and even "bad syllable" stoplists, all of which function like keyword searching and require that every conceivable synonym and euphemism be identified in painstaking detail and recorded by the software manufacturer or in some cases the customer;

- "bad site" lists, identitied through keyword stoplists, which block at the domain or host level, the directory level, the file level, or the IP (Internet Protocol) address;

- "bad topic" lists, which organize objectionable sites into broad subject categories devised by the product owner;

- content rating systems, which use the technology of PICS (Platform for Internet Content Selection) to block access to all unrated sites and/or to those that carry particular ratings assigned either voluntarily by site owners on the basis of a self-administered ratings questionnaire or by third party reviewers, human or robot; some rating systems are based on age and others on a mix of age levels and content categories; and

- $\quad$ "bad resource" lists, which block access to services such as telnet, FTP, Internet chat (IRC), and newsgroups. 
To achieve these goals, the producers of these products rely alnost exclusively on automation to replace human eyes and brains. Software robots, either existing or customized mechanical search engines referred to as web spiders or web crawlers, are used to search for and identify unacceptable Internet content. Some products also employ a small complement of staff to review a correspondingly small proportion of sites identified by the software robots (Censorware Project 1997). An alternative approach that one or two products offer is a programming "shell" that customers use to create their own stoplist entirely; in these products there is no pre-loaded list of prohibited words, phrases, sites, or categories.

Since in the case of the majority of products the process of identifying objectionable content on the Internet is almost entirely automated, the current language that is being used to describe their Internet content search functions-searching, browsing, surfing, navigating, analyzing, reviewing-should be regarded as essentially metaphorical. The search process is much more accurately described as pattern or character or string recognition, and, to be even more precise, as exact-match character recognition. Nonetheless, one product misleadingly describes its software as a "state of the art, context sensitive phrase filtering 'engine' to identify objectionable web sites," claiming that it is "90 percent effective without even knowing where the objectionable material is" (CyberSitter 1997).

The magnitude of the task that the producers of filtering and rating software have undertaken is formidable. With one estimate putting the number of new sites appearing each day at 3,000 in the U.S. alone, the Internet is a dynamic phenomenon that leaves product owners shooting at moving targets-speeding targets, actually. The most recent estimate of the size of the web is 320 million web pages currently accessible to casual browsers, a number expected to grow by 1,000 percent in the next few years. Of this total, the most comprehensive index of scientific information alone on the web covers only 34 percent of all indexable pages (HotBot), and other search engines perform even more poorly, AltaVista at 28 percent coverage, Northern Light 20 percent, Excite 14 percent, and Lycos at 3 percent (Lawrence and Giles 1998, 100).

Various products also provide other capabilities: to manually or automatically download current updates to stoplists, sometimes as often as weekly; to restrict access to everything except a list of sites containing content deemed suitable for children; to block all unrated sites; to develop, edit, or add your own list of offensive words or sites; to obtain a report of all sites visited or site violation attempts; to issue warnings; to restrict access to the computer if a certain number of forbidden sites is accessed or even shut down the Internet connection; to restrict access based on time of day or on total Internet time used; to block email; and, to block out-bound transmission of credit card numbers, family name, home address, and telephone number.

Although age-appropriateness is the official concern of the product owners and marketers, there is no standardization in software capabilities and policies. While most of the products have a pre-programmed stoplist of words, phrases, sites, and topics deemed objectionable, few permit customers to view this stoplist. Indeed, the majority regard their stoplist as a highly valuable commercial trade secret; curiously, some of the most secretive product owners permit customers to view their regular stoplist updates. However, very few perm it customers to disable the stoplist (Schneider 1997b). 
The question of how such secrecy protects the parent and other consumers must be posed: Why would disclosure of ingredients on food products, a well-established consumer practice, be more important than disclosure on a "mind product"? One wonders whether parents would buy an unlabelled can of soup or tin of baby food.

Most of the products organize their targeted sites into subject groupings or categories. However, these categories are not standardized across the marketplace so there is no uniform classification system or authority control, no MARC-like record for classifying and describing a site. Some products have only three or four categories in their subject list, while others have up to 30 ; the typical product has 10 to 15 categories. It should also be noted that some products often assign an undesirable site to multiple categories.

Typically, product categories reach far beyond sex and violence. As Schneider has observed, the categories "read like a laundry list of human concerns, with some venal sins thrown in" (Schneider 1998, 37). One product has, for example, in addition to four categories for sex and violence (violence/profanity, partial nudity, full nudity, and sexual acts), eight other categories: gross depictions, intolerance, satanic/cult, drugs/drug culture, militant/extremist, sex education, questionable/illegal and gambling, and, alcohol and tobacco. In contrast, another product has 13 primary subject categories: adult and mature subject matter of a sexual nature, pornography or adult oriented graphics, drugs or alcohol, illegal activities, gross depictions or mayhem, violence or anarchy, hate groups, racist groups, anti-Semitic groups, advocating of intolerance, computer hacking, advocating violation of copyright laws, and, any site publishing information interfering with the legal rights and obligations of a parent or the product's customers. Still another product categorizes sites under the following five headings only: adult/sexually oriented, adult/violence, gay/lesbian activities, advocating illegal/radical activities, and, advocating hate/intolerance. And yet another uses only four categories: sexually explicit, violence/hate speech, drugs/alcohol, and gambling.

This cursory overview shows that product manufacturers are targeting widely divergent materials based on widely divergent criteria. This variation is reflected in the number and range of Internet sites that are blocked, with some products reporting as few as 15,000 and others as many as 138,000 sites (Oder 1997,41 ). One Internet rating product reports that it has rated 1.5 million URLs (NetShepherd 1997).

In spite of the wide divergence among filtering products, several areas of commonality can be identified. First, all of them are commercial products. Pricing policies vary widely, with U.S. prices starting from $\$ 25$ or $\$ 30$ for one workstation and $\$ 10$ per LAN workstation for the initial installation and annual update fees ranging from $\$ 30$ for one workstation up to $\$ 1,500$ for 100 workstations and $\$ 4,000$ for 250 . In one customer incentive scheme the product is supplied "free" with the purchase of an operating system.

Another area of commonality among products is that none of them notifies site owners of blocking or rating decisions. It is only by accident that an owner would discover their site had been targeted; and complaints about inappropriate designation of sites are frequently ignored or dealt with very slowly by some software producers. Sites critical of CyberSitter, for example, have recently sued the product owner Solid Oak Software for blocking them (Schneider 1997b, 114), and others have threatened to take legal action against CyberPatrol for assigning their sites to what they allege are unjustifiable and defamatory categories (Meeks and McCullagh 1996). 
Also common to all of the products is that none is created through the expertise of credentialed librarians, either as site surfers or evaluators, product developers, marketers, or senior corporate managers. Perhaps the absence of librarians in these businesses explains in part why so few of them have any library and school customers (many have none, others 50 to 100 ).

And yet they all claim to have qualified staff. One product explains that it employs a team of "skilled Internet surfers" to locate questionable sites, which are then evaluated by "staff members" and possibly an advisory committee of "parents, teachers, and community members." This work is supplemented by "pattern blocking technology which detects words in URLs, chat, or newsgroup names that indicate inappropriate content" (SurfWatch 1998). However, a recent newspaper account describes the staffing practices of one product. Three shifts of workers - averaging 18 or 19 years of age, hired on the basis of being "Internet and computer savvy," paid $\$ 7$ per hour working in four-hour shitts-wade through 10,000 sites a day based on a four-page instruction sheet. They stay only four to five months on the job (Peter Lewis in the Seattle Times, December 17, 1997, quoted by Thompson 1998, 7).

NetShepherd has developed its own third-party "rating community" of 1,500 people who "review and democratically rate" Internet content, claiming to have rated 1.5 million URLs in a mere six months or so (NetShepherd 1997). Nothing is disclosed, however, about the professional qualifications of this community, how they are selected, who selects them, what they are paid, what sort of quality control over their work is in place, or what sort of retrieval testing is done to ensure accuracy and consistency in the resulting product. It is apparent that Internet entrepreneurs need to be reminded that full disclosure is the only responsible consumer option if they have any interest in establishing long-term credibility with the library community and the general public.

\section{Indexing theory implications for filtering and rating Internet content}

What is the relevance of indexing and retrieval theory to these software products? Even though their purpose is to be able to control and prohibit access to information and images rather than to facilitate their access, the intellectual operations involved in identifying and describing expressive content for targeting are similar to those employed in conventional retrieval systems-as are the problems and challenges.

The goal of indexing in conventional retrieval systems is to provide a systematic guide to the contents of information records. More generally, the goal is to name information, to gather together ideas into categories so that a searcher can identify everything on a subject. In order to do this, the indexer must decide first what concept or characteristic is to be represented, then what name to give the concept or characteristic, and finally how to organize the designated names (descriptors) into a searchable database.

There is also a very special feature of indexing operations and retrieval systems: materials both for and against a subject are regarded as being "about" the same topic and are therefore normally gathered together under the same classification number and under the same index term. Additional linguistic devices connect and control related terminology to maintain consistency and avoid redundancy, hence one element in the concept of 
authority control. So, for example, in order to provide access to the literature on abortion as an ethical issue, both abortion choice and anti-abortion materials are classified under the same number in the Dewey Decimal Classification (179.76 Abortion under 179.7 Respect and disrespect for human life), and in the Library of Congress Subject Headings under the generic "Abortion-Moral and ethical aspects." Even an index term such as "Pro-life movement" will encompass oppositional critiques. In short, indexing and retrieval systems are a kind of "fuzzy system," designed to accommodate however imperfectly both vagueness in language as well as exactitude, and partial truth in human understanding just as easily as received wisdom.

Like language itself, indexing operations for retrieval are ambiguous. Since the indexing process is bounded by language, the representation of subjects is similarly ambiguous, fluid, susceptible to nuance, imprecision, inconsistency, cultural variation, and unpredictable change over time. These operations for representing subjects in an indexing system pose immediate problems for effective identification, control, and retrieval of materials. The problems concerned are the concepts of aboutness, specificity, consistency, exhaustivity, relevance, and universality.

Aboutness is the central problem of indexing: how does one decide what a text is about? How does one determine context? Specificity is the opposite problem: how does one decide which aspects of a text will be represented, and with which terms? Consistency is also involved in the problem of indexing specificity, because synonymous terminology must be identified and controlled, and hence the need in part for authority control. Exhaustivity involves the question of how many concepts from a document will be represented. Relevance is related to exhaustivity in posing the challenge of identifying and indexing only those aspects that people want information about. Finally, the assumption of universality challenges all indexing operations. Universality is the pervasive-and mistaken-belief that there is a one-to-one correspondence, an absolute link, between concept and descriptor that transcends not only culture, ideology, and time but age and reading differences as well. Universality assumes the existence of one and only one cultural perspective-and generally it is the indexer's.

With Internet stoplists of words, sites, and topics, the problems of identifying and describing concepts are similar to those encountered in free text searching in conventional retrieval systems. Free text searching works on the assumption that what a text is about can be succinctly captured in individual words and phrases-discrete strings of characters. Free text searching is therefore context-and concept-free, permitting no human intermediary to impose an intellectual structure for effective retrieval. It is word focussed, not concept focussed. Thus, when the goal is to block or rate expressive content, the problems approximate those involved in free text searching in conventional retrieval systems.

Such problems are ubiquitous and profound. In one type of blocking program option, for example, " $x$ 's" or blank spaces are substituted for the offending word or phrase. The result of this literalness is to make gibberish of the text. Schneider has reported one instance of this in a search she did to verify the OCLC record for Our Tribe by Nancy Wilson (Schneider 1997a). With the filtering product in place, the title was shown as:

Our tribe : \$b folks, God, Jesus, and the Bible /

Sc Nancy Wilson. 
And there were odd blanks in the 650 fields:

156500 \$x Religious aspects \$x Christianity.

$156500 \quad$ \$x Biblical teaching.

Similarly, a title on human sexuality by the well-known Bishop Spong was represented as:

Living in sin?: \$b a bishop rethinks human

\$c John Shelby Spong.

And yet the 650 field was:

136500 Sex \$x Religious aspects \$x Christianity.

But the most egregious blocking makes the offending words, sites, and topics disappear, utterly invisible to searchers, so that they are completely unaware that suppressed information even exists. The only way to discover this, however, would be to search for already known items, sites, or topics. For exaniple, in the "Society and Culture" category in Yahoo! is a heading for sexuality, but searching with one of the filtering products in place makes this topic simply vanish from the subject listing (Carroll and Broadhead 1996, 568-569).

Also blocked and invisible to the searcher using some filtering products is anything that remotely concerns homosexuality, lesbianism, or bisexuality - sites such as the Queer Resources Directory, the Critical Path AIDS Project, and the HIV Info Center; gay political and journalism newsgroups such as clari.news.gays, alt.journalism.gay-press, alt.politics.homosexual, soc.support.youth.gay-lesbian-bi; and chatrooms for gays and lesbians. One product prevented access to the entire library web site of the Archie R. Dykes Medical Library because it blocks homosexuality and therefore the term "dyke" (Chelton 1997). As a company spokesperson for one product stated: "We filter anything that has to do with sex. Sexual orientation [is about sex] by virtue of the fact that it has sex in the name" (quoted by Meeks and McCullagh 1996).

However, targeting sex also blocks the newsgroup dedicated to Star Trek's Captain Jean-Luc Picard, alt.sexy.bald.captain, the NASA site marsexplorer.com, the works of poet Ann Sexton, sexual harassment sites, and information about sexually transmitted diseases. And in 1996 the word "couple" was added to one product stoplist, resulting in part of the White House site being blocked because "couples" appeared in a reference to the Clintons and the Cores (Dority 1996, 19). The same product also blocked the site for Super Bowl $X X X I$ and a hockey site because of news that a player had been sidelined due to a groin injury (Newsletter on Intellectual Freedom 1997, 29). And one of the earliest and most widely publicized examples was the blocking by America Online of the word "breast" from some areas of its service.

But most products do not stop there. Some also block numerous feminist sites such as NOW, the National Organization for Women, feminist newsgroups, and sites such as alt.feminism, soc.support.pregnancy.loss, and soc.support.fat-acceptance. The sites of the Quakers, the American Association of University Women, and the U.S. Central Intelligence Agency have been blocked. One product blocks sites run by gun rights and gun advocates groups such as the Silicon Valley National Rifle Association. The entire HotWired domain is blocked by one product, as is a site dedicated to the safe use of fireworks. Some parts of 
sites run by animal-rights groups are blocked because of depictions of syphilis-infected monkeys and other animal abuses.

One product blocked the important Holocaust archive and anti-revisionist resource site Nizkor for a time, because it contained "hate speech" (Wallace 1997c). Other targets have been newsgroups of pagans, naturists, and others such as misc.activism.progressive, misc.headlines, misc.health.aids, misc.health.alternative, talk.abortion, talk.euthanasia, talk.politics.drugs, alt.atheism, alt.teens, and 220 newsgroups prefixed alt.support (Thompson 1998, 7). Also blocked was the Planned Parenthood site. In still another case, a product blocked the site of reference book publisher Sinauer Associates, information about sexual dysfunction, and Kierkegaard (B.C. 1998, 25). One product blocked the entire Echo ISP, New York City's oldest online community, another articles about AIDS and HIV from clarinet's AP and Reuters, another the University of Newcastle's computer science department site, and another all mailing lists run out of cs.colorado.edu.

In an extensive report entitled "Blacklisted by CyberPatrol: From Ada to Yoyo," a group of writers and Internet activists calling themselves the Censorware Project have documented a large number of sites that CyberPatrol has blocked inappropriately, and concludes that correcting errors is a low priority for the software producer (Censorware Project 1997). The report's title comes from two of the blocked sites discovered to be listed in the product's "full nude" and "sexual acts" categories: one, the site of a political committee in Ada, Michigan concerned with responsible township government; the other, a student run server at Monash University in Melbourne, Australia that has 5,000 student accounts and over 6,000 web pages.

The Censonware Project identified hundreds of unjustifiably blocked sites. Among them were an award-winning pet care site; the site for a Nike poster advertising shoes named after Penny Hardaway; the MIT Project on Mathematics and Computation site; a site about bodybuilding products and protein bars; the "Sunset Strip" neighborhood of Ceocities that contains 90,000 individual sites about rock, grunge, punk, techno, and the alternative music scene; the National Academy of Clinical biochemistry site; a server at the Chiba Institute of Technology in Japan; the site of the U.S. Army Corps of Engineers Construction Engineering Research Laboratories; Mother Jones magazine online; the Envirolink site, a clearinghouse of environmental information; the HIV/AIDS Information Center site of the Journal of the American Medical Association; and numerous gay sites including one that advertises gourmet coffees, teas, food, and gifts, and another, one of the most contentious blocks, "West Hollywood," which is a GeoCities neighborhood that contains over 23,000 gay and lesbian sites with over 50,000 webpages. Over 50 Internet server machines were also blocked outright, including one, members.tripod.com, that has almost 800,000 members and contains 1.4 million webpages blocked on all twelve of CyberPatrol's categories. Well over 300 newsgroups were also blocked, including 100 groups in the entire rec.games. * hierarchy, 220 groups in the alt.sup* hierarchy, the soc. support* hierarchy, many groups in the soc. ${ }^{*}$ hierarchy, and the alt.cyber* tree.

These examples serve to illustrate the variety of problems that are equally inherent in accurately identifying negative targets for Internet blocking programs as in identifying positive targets for conventional retrieval systenis.

Consistency in the assignment of index terms is a well-known problem in retrieval research. Inter-indexer consistency studies show over and over again that there is a great 
deal of variation in levels of agreement among indexers on their assignment of terms representing the subject content of a text. Consistency among indexers ranges from a minimal 4 percent to 82 percent (Markey 1984, 155-160). Greater levels of consistency are achieved when indexers choose terms from a controlled vocabulary, with consistency scores then reaching 34 percent but with the same ceiling (161).

In the light of these long-known patterns, why would Internet filtering and rating products achieve the much higher rates of indexing consistency, exhaustivity, specificity, and certainty that their advertising rhetoric claims? Their scripts and those of their advocates are full of unqualified assurances of prevention, child safety, protection, safeguarding, 24-hour monitoring, empowering parents, peace of mind, keeping an eye on everything, complete control, truly complete solutions, and very sophisticated methods of controlling access. (Some products, with names like CyberSnoop, CyberSnitch, and Tattle-Tale, offer surveillance features that may trouble some parents concerned about developing relationships of mutual honesty and trust with their children.)

Even when the promotional claims are more qualified, however-when, for example, the promise is to provide for the "relative safety" of children exploring the Net, or there is an explicit disclaimer of responsibility either for accuracy or completeness of information or for errors or omissions (CyberPatrol 1997a) - the vast majority of parents and other consumers will not long remember the qualifiers or the "fine print," if indeed they notice any of it in the first place.

In reality, the new technologies do not live up to their promises at all. In a recent small-scale study conducted by Consumer Reports of 22 easy-to-find web sites that had been judged by investigators to be inappropriate for young children, not one of the four most common software blockers-CyberPatrol, CyberSitter, NetNanny, and SurfWatchblocked all of the sites. NetNanny failed to block any of the 22 sites, while 14 were blocked by CyberSitter, 16 by CyberPatrol, and 18 by SurWatch; and only 3 sites were blocked by Internet Explorer (Is your kid 1997, 30). These rates are far below the levels that parents and other consumers have been led to expect. Another small-scale study by PC World found marginally better performance: two of the five products tested were effective in blocking all ten of the adult-oriented sites in the evaluation (Internet filters 1997).

The most extensive study to date, The Internet Filter Assessment Project (TIFAP), was coordinated by Schneider and involved 40 volunteers who tested 13 products on 100 questions over a six-month period April-September 1997 (Schneider 1997b). All of the products were found to hinder information retrieval, blocking innocuous occurrences of words and many sites with information similar to what would be found in libraries-but at the same time permitting access to offensive sites. One product blocked "good sites" 5 to 10 percent of the time while pornographic sites slipped through about 10 percent (Schneider 1998, 37). The poem "pussycat, pussycat" was blocked consistently, but never "Roger" although it is Australian slang for penis. Sites for "Alternative Journals" and "Activist Groups" were blocked by two products. Other sites blocked were those of hate groups, press releases on sex offenders, an interview with Leslea Newman, a list of jockeys, and safe sex information (Schneider 1997b, 93).

Why such low rates of consistency, exhaustivity, specificity, and certainty? The answers are found in the essential ambiguities of language itself and in the challenges that language 
presents for both free text searching and subject identification. Every language has a multitude of synonyms and antonyms and euphemisms, puns and double entendres, and in English there are generally slippery terms like "objectionable," "patently offensive," "degrading," "harmful," "morally dangerous," and "pornographic." There are a number of notoriously vague legal concepts in North America-"obscenity," "undueness" (as in undue exploitation of sex), and "community standards"-_as well as newer concepts being lobbied for legislative sanction, among which the most prominent in the U.S. are "indecency" and "harmful to minors."

There are homographs, words with multiple meanings, which have at least one meaning that is non-sexual in nature, words such as "gay" and "couple," as well as hundreds if not thousands of other terms-many slang--that refer to sex, sexuality, and genitalia. Then there are proper names such as Butts and Dykes and Gay. We also witness new terms invented, such as "Bobbitt," "cyberporn," and former Canadian Prime Minister Pierre Trudeau's "fuddle-duddle," while older terms are twisted into new meanings, such as "rock and roll," which was originally African American slang for sexual congress, "snow" for cocaine, "political correctness," and "family values." Pejorative epithets are sometimes appropriated by marginalized minorities and turned into affirmations of group pride, terms such as "queer" and "nigger." Terms also go out of fashion, such as "French letter" for "condom," "hooch" for alcohol, "cats" for men.

Then there is the problem of English usage outside the U.S., particularly the problem of slang- "randy" and "the full Monty" are British examples. There are also foreign terms imported into English in some regions, as in the example of "merde" in a 1984 book by Geneviève Edis entitled The Complete Merde! The REAL French You Were Never Taught in School, or the Hebrew term "schmuck," which is extremely pejorative slang for penis.

There are also inherent category problems in all indexing systems. As Trinh T. Minh-Ha has written, categories always leak (Trinh 1991, 119). Complex concepts do not fit into simple compartments. The word, phrase, and site identification strategies of the blocking products pigeonhole ideas and impose ideological agendas. Is all violence of the same kind? Is a punch the same as an execution? Should nudity and sex be categorized together? Is erotica the same as the sexually explicit? How would redeeming social value be introduced into any analysis?

While some of the software products acknowledge the existence of a value system or some sort of ideological agenda in their filtering and rating operations, others resolutely deny the charge. CyberSitter, for example, denies that it has a political agenda and that it blocks only sites "that meet a pre-defined criteria... without exception." The product goes a step further, claiming that it "has no agenda of any kind, unless you consider protection of children a hidden agenda" (CyberSitter 1997).

In contrast, CyberPatrol states that it operates on an explicit criterion: "In evaluating a site for inclusion in the [blocking] list, we consider the effect of the site on a typical twelve year old searching the internet unaccompanied by a parent or educator" (CyberPatrol 1997a). The product also states that its blocking criteria pertain to "advocacy information: how to obtain inappropriate materials and or how to build, grow or use said materials. The categories do not pertain to sites containing opinion or educational material, such a the historical use of marijuana or the political situation in Germany during the 1930s and 
subsequent World War II" (CyberPatrol 1997b). Another product makes no apology for its choices:

We don't simply block pornography. That's not the intention of the product. The majority of our customers are strong family-oriented people with traditional family values. Our product is sold by Focus on the Family because we allow the parents to select fairly strict guidelines" (quoted by Meeks and McCullagh 1996). However, most products are far more ambiguous in articulating who their target audiences are. One product describes its activity as filtering sites that "may not be suitable for all audiences" (NetNanny, undated).

Whether the agenda is hidden or explicit, however, indexing decisions are the interplay of the indexer's judgment and the text. The naming of information through indexing is of necessity personalized: there must be a perspective, a viewpoint. This is clearly evident, for example, in CyberPatrol's reference standard, its hypothetical twelve-year-old, and in nuanced phrasing of its blocking criteria based on a level of "possibly objectionable content" (CyberPatrol 1997a) and "potentially objectionable material" (CyberPatrol 1998). Other products are not so explicit.

And since the naming of information for retrieval involves control, an exercise of power is involved (Olson 1996, 4-5). The ethical exercise of that power requires continuous self-awareness and self-reflection in the decisions that the indexer makes. It also requires that decisions and their rationale are made public and subjected to public debate.

The urgent need for disclosure and scrutiny introduces an even more disturbing aspect of the exercise of power and ideology by some software products. Some products are being used to silence public debate. In retaliation for criticism on the Internet, CyberSitter's "bad word" list was revised last year to block access to sites containing the phrase "Don't Buy CyberSitter!" as well as to the site for Peacefire, a student organization opposing Internet censorship in any form. CyberSitter has also blocked the site for The Ethical Spectacle (www.spectacle.org), apparently in retaliation for the Webzine's criticism of the company that owns the program, Solid Oak Software; and in fact, even communicating with CyberSitter to ask questions about its blocking of the site prompted a message from the product owner, Solid Oak Software, Inc., accusing the inquirer of harassment or political motivation (Shallit 1997).

And CyberPatrol has similarly gone to extreme lengths to suppress criticism, blocking sites that oppose it or its approach to content control. A recent example of the product's attitude towards criticism is the blocking of web pages pertaining to Sex, Laws, and Cyberspace, by Jonathan Wallace and Mark Mangan, published by Henry Holt in 1996 (Wallace 1997a, 1997b). Electronic Frontier Foundation's censorship archive, the League for Programming Freedom at MIT, the MIT Student Association for Freedom of Expression, a group opposing software patents, and a site critical of America Online, alt.aol-sucks.moderated, are also sites that have been blocked by one product or another.

To sum up the lessons of indexing theory, Internet filtering and rating systems would appear to be a worst case scenario in the organization of information. In these commercial operations, text and images are dissected on the basis of a pre-determined corporate value system into selected parts, which are then highlighted for prohibition or access restrictions. Wholeness and context are sacrificed. Integrity of text and respect for reader are both ignored in favor of a single, uniform standard of "safe" words and "safe" ideas that 
disregards age level. The result is indexing activity that is arbitrary, vague, overbroad, and incapable of adequate discrimination by age and topic.

The great irony is that sites arguing against the perceived enemy will also be restricted or suppressed: anti-gay sites, anti-drug sites, anti-sex education sites, anti-abortion sites, sexual abstinence sites, even sites dedicated to recovery from sexual abuse.

In spite of the denials of some producers of these products, any operation that identifies words, phrases, topics, and sites for blocking is of necessity imposing an ideological agenda or value system. In the approach followed by these commercial products, context is ignored and one four-letter word becomes more important than 400 pages of story. Margaret Laurence, the great Canadian novelist, is said to have called this "snippet censorship," the practice of basing one's judgment of a work on excerpts, offending words or phrases, and scenes lifted out of context (Carver 1997). How, for example, would the products treat the Bible? According to what criteria? Would they rate each story individually? Or even individual words within each story?

When blocking and rating decisions are made by unknown third parties with unknown qualifications and unknown ideological agendas, the danger to public debate is palpable. With a broad sweep, these products indict all representations of violence, sex, hatred, and other targets as equally bad, and as especially bad for young people.

To sum up, "censorproofing" the Internet-sanitizing and making it safe from potentially controversial content-is doomed to failure for many reasons:

- new sites

- new terms

- new issues-new subjects; old subjects

- region or culture-specific terms

- variable perceptions of offensiveness, indecency, harmfulness, and so forth

- variable perceptions of age appropriateness

- imprecise and variable descriptor terms

- text in languages other than English, and foreign language words adopted into English

- culture-specific values and priorities, for example, marked differences in American and European attitudes to violence, sex, and nudity. 


\section{Reader response theory implications for filtering and rating Internet content}

The problem of ambiguity in language is highlighted by reader response theory. Reading is the process of getting meaning off a page, a unique experience each time it is done, but we have hardly begun to learn what it is we are doing when we read (Manguel 1996). The response of a reader to any text-whether a text is viewed narrowly as print on pages or more broadly as any symbolic representation from which we draw meaning -is seen as a confluence of the text itself, the reader's personal history, the reader's reading history, and the reader's motive for reading.

Since meaning is embedded in the context in which information is used, the root of library policy on Internet use must be the concept that the context of the use of information is critical to how appropriate the information is in a given institutional setting (Davison 1996). For example, studying hate propaganda sites on the Internet is a much different intellectual and educational activity than adding racial slurs oneself. Reading is not endorsing.

To a certain degree, therefore, readers participate in creating the meaning of a text based on their own reading history, their own personal filter of cultural, moral, and aesthetic values, and their own reading motivation. In this dynamic, the meaning that a particular reader ascribes to a text may or may not approximate the author's original conception-or, for that matter, any other reader's.

According to this view of reader response, then, far from being a fixed and objective thing that every reader perceives identically, a text is somewhat ambiguous, fluid, subjective, susceptible to multiple meanings and contrary interpretations. Reader response theory is captured in a familiar expression: It's in the eye of the beholder.

What reader response theory reveals are the twin requirements for any blocking or rating system: prophecy and clairvoyance. Anybody attempting to control creative expression in such a fashion has to be able to predict the future about probable-and even improbable - censorial targets, which in turn means being able to read the minds of potential complainants and figure out their tolerance limits on pretty well every imaginable subject. Surveys of challenges to library materials confirm how unpredictable this task is: on the order of 90 percent of challenged titles in library collections are only targeted once each in any given period of time (Schrader 1996, 1997).

Here are some specific examples of reader complaints from my own censorship research (Schrader 1995) that reveal how unpredictable the ways are in which people uniquely interpret texts:

- Adultery for Adults by Joyce Peterson, about which the complainant said: "The title alone is offensive - who needs instruction in adultery?! Zero value - didn't read entire book - it is trash! Can't recommend better book - the person who would read this book needs a marriage counsellor not another 'how-to' book."

- Darling I am Growing Old by Gene Stone: "The book portrays 'lust' from cover to cover....Senior people should be a positive example to the younger generation when immoral degeneracy has crept in, yet this book depicts seniors as an immoral sexy generation, who are unfaithful to their spouses, men and women 
alike. I would want to hope that the book does not portray life in our senior citizen complexes."

- Ms Magazine: "Feminist literature undermines the sanctity of family life."

- The Piercing by John Coyne: Objection to portrayal of Roman Catholic Church: "When I think of all the Protestant hands this book has been through."

- In the Night Kitchen by Maurice Sendak: "Nudity, unpleasant story no child could enjoy."

Reader response theory is especially relevant in considering text for children, taking into account their enormous variation exhibited by children in emotional development and psychological maturity not only at different stages of growth but at the same age as well. Parental experience and formal research affirm that babies respond to language from earliest infancy, and by 12 to 18 months begin to recognize picture/word association, an important first step to reading, and by age three most children enjoy selecting and borrowing books from library collections.

But maturity is not a simple function of biological age: one 12-year-old is nearly an adult, another is closer to childhood. The average age of puberty is around 10 or 11 , with wide variation ranging from seven to 17 , and yet some adults are horrified that texts geared to those ages deal with menstruation and awakening sexuality. Those same adults are even more horrified that parents are encouraged to begin talking to children as young as three about their bodies and about what is appropriate touching and what is not. "Children must be encouraged to tell a parent if someone tries to touch their private parts. They must know that no one has a right to do that and if anyone tries, they must come and tell the parents immediately" (Landers 1998).

To accommodate the vast diversity of needs represented across such broad age groupings means that each young person must seek out their own level of reading, viewing, and listening interests, both individually and continuously, under the guidance of their parents or guardians. Moreover, most young people who are readers tend to "read up," that is to say, they read above the reading level designations assigned by publishers, reviewers, and librarians. Internet content is no different. Filtering and rating decisions that treat it as if were fixed for all children regardless of age and maturity is an inadequate and flawed approach to child development.

\section{Summary}

What the principles of indexing theory and reading theory tell us is that Internet filtering and rating technologies are theoretically unworkable. It is not that they are technologically unworkable or technologically limited. It is that the essential ambiguities of language, text, reader, indexing, and retrieval ensure the failure of automated searching. The problems of identifying and describing Internet content for purposes of control and prohibition are intractable: new sites, new terms, new issues, the world cacophony of languages, variable interpretations of meaning, variable perceptions of offensiveness, variable perceptions of age appropriateness, infinitely variable descriptors, and variable cultural norms. 
These ambiguities and dynamics prevent blocking and rating software from ever being successful in controlling the world of ideas at a level of consistency, exhaustivity, specificity, and certainty that would be sophisticated enough to satisfy critics, reassure parents, and relieve librarians and teachers of unpleasant encounters with complainants. Human language is just too unstable, words and meanings just too indeterminate, too elastic, too mutable, too imperfect. As one critic has put it, "safe-only access can not happen because individual perceptions of safe are as varied as the number of sites on the Internet" (Crosslin 1998, 52).

The American Library Association's "Statement on Library Use of Filtering Software," an explanatory document accompanying the "Resolution on the Use of Filtering Software in Libraries" that was adopted by ALA Council on July 2, 1997, concluded that:

Library use of blocking/filtering software creates an implied contract with parents that their children will not be able to access material on the Internet that they do not wish their children read or view. Libraries will be unable to fulfill this implied contract, due to the technological limitations of the software, thus exposing themselves to possible legal liability and litigation (American Library Association 1997, 120).

In response to criticisms of software imperfection, apologists are quick to argue that current technology is "good though not perfect," "rapidly improving," "reasonably accurate," "extremely effective but not foolproof," that "some protection is better than none," that " $80 \%$ is better than nothing." One public library director calls WebSense "80 percent effective" (Oder 1997, 41).

We need to ask if smoke detectors that worked 75 or 80 per cent of the time would be better than nothing-especially when the timing of the operational phase is unknown and unknowable. Moreover, to extend the analogy, we might ask how acceptable such smoke detectors would be if they not only reacted to smoke but also to incense, garlic, sweat, perfume, or other unpredicted and unpredictable triggers. Or, more radically yet, what if the detectors promised home safety but disclosed nothing about what that meant or how it would be realized.

Yet the very names of the software products-nanny, patrol, shepherd, sitter, watchconjure up images of unqualified protection, safety, guidance, and comfort. NetNanny advertising, for example, says: "NetNanny is watching when parents aren't."

But instead of fulfilling these explicit advertising promises, what the new products offer is the illusion of success - an illusion that comes with a high price tag. One price is a false sense of security. Its twin is a false sense of confidence that all appropriate information will still be retrieved when one searches the Internet.

Another price is intellectual freedom. Since indexing for any retrieval system is about the control of ideas as much as it is about access, the dangers to intellectual freedom are always imminent. The crude, paternalistic strategies adopted by blocking and rating products should serve to remind us that authority control keeps some voices out just as easily as it lets others in. Internet blocking software is like pertorming brain surgery with a chainsaw.

I would like to see librarians in all sectors of service to society enter into the public debate about the Internet through their institutions and associations, as well as individually by 
virtue of professional training. I would like to see them help refocus public debate around fundamental social policy objectives and the strategies to achieve them, to work to dispel fear and moral panic about the Internet and kids, and to help instead to promote critical thinking and understanding. As Herbert Foerstel told a meeting called in response to complaints about the inclusion of certain materials in a Maryland library collection: "Tell us what you want to read, rather than what you don't want others to read" (emphasis in original, Foerstel 1994, 30).

We need to implement acceptable use policies, AUPs, that make explicit the respective rights and responsibilities of students, parents, and school officials for acceptable behaviour on the Internet. Dillon (1996) and Ingvarson (1996) have described in considerable detail the elements and principles that should go into such policies, and the Internet is full of examples easily retrieved (see, for example, The Internet Advocate site, a web-based resource guide for librarians and educators interested in providing youth access, at <http://www.monroe.lib.in.us/ Ichampel/netadv.html>

We need to expand school library collection development into Internet sites; to educate parents about child safety issues on the Internet and how to raise "Net smart" children to ensure that school library policies on collection development, intellectual freedom, Internet access, and materials reconsideration are understood; to forge alliances among different types of libraries as well as stronger community links; to provide in-house staff training and regular refresher sessions; to participate in the development of professional association policy statements and positions; and to support research efforts that investigate software product claims.

Above all, we need to expand information and library literacy into the school curriculum, with school librarians in the lead to teach the skills of both information searching and critical thinking. As a recent New York Times editorial, critical of a legislative initiative to require anti-pornography filters on school and school library computers, concluded: "Given the limitations of filtering technology, the best way to protect children is to teach them how to use the Internet. A software program simply cannot do that" (New York Times 1998).

By way of postscript, I would like to see school librarians caution parents and individuals about the serious shortcomings of internet software products that promise protection and monitoring, shortcomings that are not merely technological but nore importantly moral, for blocking and rating systems do not help young people learn how to assume the responsibilities of adulthood, how to make independent critical judgments, how to say no, how to live vicariously through story rather than dangerously through experience. As one librarian has asked rather rhetorically, do parents really want to turn their children's value systems over to a software vendor? (Crosslin 1998, 52) Would they trust a neighbour they do not know with all decisions about what their children will be permitted to access on the Internet?

None of the strategies of blocking and rating can accomplish anything more than the illusion of success. They attempt to impose an objective, simplistic standard of description and measurement on what is essentially a complex and highly variable matter of personal tastes, individualized family values, highly variable perceptions of age appropriateness, and widely varying thresholds of social tolerance. The products take judgment, control, and accountability away from professionals in favor of third-party commercial interests that rely 
on faceless and unaccountable software robots for exact character matching. Automatic searching for objectionable content has no more chance of attaining an acceptable degree of success than automatic translation has. As Schneider succinctly describes them, "Internet filters are mechanical tools wrapped around subjective judgment" (Schneider 1997b, xiv).

I do not believe that bad ideas or bad images produce bad kids. Nor do I believe that there is a shred of evidence to support this simplistic argument. We should worry much more about a lack of information than about too much or the wrong kind. Today, children of ten have potentially more information available to them than their grandparents had in an entire lifetime. There are no reasonable grounds to fear contagion or uncritical acceptance of ideas if children have strong family values. What should concern librarians is young people who have access to only one view of the world, young people brought up with no knowledge of choice, no awareness of diversity. As one critic was quoted as saying,

Which is more harmful to children: occasional exposure to erotic material or concealment of information about preventing pregnancy and the transmission of AIDS? That's the question confronting parents, school administrators and librarians when they consider installing blocking software on computers (Wendy Kaminer, quoted by Wood 1998).

That is my own fear at any rate: too little information, never too much. Outsourcing moral authority to faceless and anonymous Internet guardians is no alternative to family responsibility, librarian and teacher guidance, and individual critical awareness. As Meeks and McCullagh (1996) have so eloquently written, "Technology is no substitute for conscience." If the analysis presented in this paper is accurate, it is irresponsible of institutions such as schools and libraries to use taxpayer money to buy products that do not work as advertised and that do not advance pedagogical goals: first we pay to obtain Internet access, and then we pay again to get rid of it.

My final word goes, fittingly, to a twelve year old girl-the typical young person for whom one of the filtering products is explicitly marketed-who wrote a letter to the local newspaper opposing censorship of the Internet at the Dundas Public Library in Ontario, Canada. She said:

I am twelve years old and I go on the Internet all the time, on average $1 / 2$ hour per day. Of all the time that I have been using it, (more than four years now), I have never seen or heard about any pornography pages or sites... To me, the Internet is a way to explore the world without going anywhere. When I am on the Internet, it is my responsibility to pick and choose which pages are appropriate for me. If you are worried about your child's choices, explore it together (Blonski 1997).

I would like to record my sincerest appreciation to my colleague Dr. Dianne Oberg for valuable insights in the preparation of this paper and for reading an earlier draft. 


\section{References}

American Library Association (1997). Statement on library use of filtering software. Newsletter on Intellectual Freedom, September, 119-120.

B.G. (Goldberg, Beverly). (1998). "With friends like these...." American Libraries, April, 25.

Blonski, Jackie (1997). "The Internet is an important place to learn and explore" (letter to the editor). Dundas Review, June 15, 4. <http://insight.mcmaster.ca/org...dia/ Dundas-review.15jun97.html>

Book and Periodical Council (1997). Freedom to read week kit. Toronto, Ontario: Book and Periodical Council.

Carver, Peter (1997). Battle over novel (letter to the editor). Clobe and Mail, February 7, A14.

Carroll, Jim and Broadhead, Rick(1996). 1997 Canadian Internet handbook. Scarborough, Ontario: Prentice Hall Canada.

Censorware Project (1997). Blacklisted by CyberPatrol: From Ada to Yoyo (December). $<$ http://www.spectacle.org/cwp >

Chelton, Mary K. (1997). Internet names and filtering software. Email message from <cheltonm@esumail.emporia.edu> (March 4).

Crosslin, Donna (1998). Unsafe at any modem speed (letter to the editor). American Libraries, 29, 52.

CyberPatrol (1997a). Overview: The CyberNOT Block List. <http://www. cyberpatrol.com/cp_block.htm> (May 11).

CyberPatrol (1997b). CyberPatrol CyberNOT list criteria. <http://www.microsys. com/cyber/cp_list.htm > (May 11).

CyberPatrol (1998). Internet acceptable use guide. http://www.cyberpatrol.com/ cpc.aug.htm>.

CyberSitter (1997). Frequently asked questions about CyberSITTER. <http://www.solidoak.com/cyberfaq.htm>.

Davison, Phil (1996). Censorship and the need to develop policy. In Lyn Hay and James Henri (Eds.), A meeting of the minds: ITEC virtual conference '96 proceedings ( $\mathrm{p}$. 9). Belconnen: Australian School Library Association.

Dillon, Ken (1996). Management of student access to the Internet: Issues and responsibilities. In Lyn Hay and James Henri (Eds.), A meeting of the minds: ITEC virtual conference '96 proceedings (pp. 16-23). Belconnen, ACT: Australian School Library Association.

Dority, Barbara (1996). Ratings and the V-chip. The Humanist, May/June, 19.

Foerstel, Herbert (1994). Conflict and compromise over homosexual literature. Emergency Librarian, 22, 30. 
Ingvarson, Daniel (1996). Censorship: Planning a safe ride on the superhighway. In Lyn Hay and James Henri (Eds.), A meeting of the minds: ITEC virtual conference '96 proceedings (pp. 3-6). Belconnen, ACT: Australian School Library Association.

Internet filters (1997). Internet filters: The smut stops here. Or does it? Screening five top web filters. PC World 15, 78-80. Also available at: <http:// www.pcworld.com/softwar.../articles/oct97/1510p078a.html>

Is your kid (1997). Is your kid caught up in the Web? How to find the best parts-and avoid the others. Consumer Reports, May, 27-31.

Kaminer, Betty (1998). Quoted by Don Wood in a message March 20 from <dwood@ala.org> to <itaction@ala1.ala.org>

Landers, Ann (1998). Husband has no place in bed of a young child. Edmonton Journal, February 3, E6.

Lawrence, Steve and Giles, C. Lee (1998). Searching the World Wide Web. Science, 280, 98-100.

Manguel, Alberto (1996). A history of reading. Toronto: Alfred A. Knopi Canada.

Markey, Karen (1984). Inter-indexer consistency tests: A literature review and report of a test of consistency in indexing visual materials. Library and Information Science Research, 6, 155-177.

Meeks, Brock N. and Declan B. McCullagh (1996). Keys to the kingdom. CyberWire Dispatch. (July). <http://www.eff.org/pub/Publications/Declan_McCullagh/ cwd.keys.to.the.kingdom.0796.article $>$

NetShepherd (1997). NetShepherd responds to the EPIC report 'Faulty Filters'. <http://www.netshepherd.com/fsEpicResponse.htm> (December 2).

New York Times (1998). Filtering the Internet (Editorial). New York Times, March 16, A24.

Newsletter on Intellectual Freedom, March, 29.

Oder, Norman (1997). Filtering and its contradictions. Library Joumal, 122, 41-42.

Olson, Hope A. (1996). The power to name: Marginalizations and exclusions of subject representation in library catalogues. Unpublished doctoral dissertation, University of Wisconsin-Madison.

Overview (1997). Human Rights Forum, 7, 3.

Schneider, Karen G. (1997a). Filters, homosexuality, responsibility, and so forth. Email message from<schneider.karen@epamail.epa.gov> to <web4lib@library.berkeley.edu> \{The WWW for Libraries mailing list $\}$.

Schneider, Karen G. (1997b). A Practical Guide to Internet Filters. New York: Neal-Schuman. See also The Internet Filter Assessment Project at <http://www.bluehighways.com/tifap > 
Schneider, Karen G. (1998). Figuring out filters: A quick guide to help demystify them. School Library Journal, 44, 36-38.

Schrader, Alvin M. (1995). Fear of words: Censorship and the public libraries of Canada. Ottawa, Ontario: Canadian Library Association.

Schrader, Alvin M. (1996). Censorproofing school library collections: The fallacy and futility. School Libraries Worldwide, 2, 71-94.

Schrader, Alvin M. (1997). 'Why you can't 'censorproof' your public library: What research tells us." Public Library Quarterly. 16 (1): 3-30.

Shallit, Jeffrey (1997). Query. (January 23). Email message from <terminator@solidoak.com> to <shallit@graceland.uwaterloo.ca>

SurfWatch (1998). SurfWatch filtering criteria. <http://2221.surfwatch.com/filteringcriteria/ index.htm|>

Thompson, Ken (1998). When in doubt...Filter! Filter! Filter! Social Responsibilities Round Table Newsletter, March, 6-7.

Trinh, T. Minh-Ha (1989). Woman, native, other: Writing postcoloniality and feminism. Bloomington: Indiana University.

Wallace, Jonathan D. (1997a). Subject 1: Solid Oak blocking software and Ethical Spectacle. Email message from <jw@bway.net> (January 19).

Wallace, Jonathan D. (1997b). File 5-Cyberpatrol now blocks my site. Email message from<jw@bway.net> (February 17).

Wallace, Jonathan D. (1997c). Purchase of blocking software by public libraries is unconstitutional. The Ethical Spectacle. November 9.

<http://www.spectacle.org/cs/library.html> 